Article

\title{
Colossal Permittivity and Low Dielectric Loss of Thermal Oxidation Single-Crystalline Si Wafers
}

\author{
Yalong Sun, Di Wu *, Kai Liu and Fengang Zheng * \\ College of Physical Science and Technology, School of Optoelectronic Science and Engineering and Technology \\ and Jiangsu Key Laboratory of Thin Films, Soochow University, Suzhou 215006, China; \\ 20164208051@stu.suda.edu.cn (Y.S.); 20154208020@stu.suda.edu.cn (K.L.) \\ * Correspondence: wudi@suda.edu.cn (D.W.); zhfg@suda.edu.cn (F.Z.)
}

Received: 25 February 2019; Accepted: 1 April 2019; Published: 3 April 2019

check for updates

\begin{abstract}
In this work, thin $\mathrm{SiO}_{2}$ insulating layers were generated on the top and bottom surfaces of single-crystalline silicon plates ( $\mathrm{n}$ type) by thermal oxidation to obtain an insulator/semiconductor/insulator (ISI) multilayer structure. X-ray diffraction (XRD) pattern and scanning electron microscope (SEM) pictures implied that all of the synthesized $\mathrm{SiO}_{2}$ layers were amorphous. By controlling the thermal oxidation times, we obtained $\mathrm{SiO}_{2}$ layers with various thicknesses. The dielectric properties of silicon plates with different thicknesses of $\mathrm{SiO}_{2}$ layers (different thermal oxidation times) were measured. The dielectric properties of all of the single-crystalline silicon plates improved greatly after thermal oxidation. The dielectric constant of the silicon plates with $\mathrm{SiO}_{2}$ layers was approximately $10^{4}$, which was approximately three orders more than that of the intrinsic single-crystalline silicon plate (11.9). Furthermore, both high permittivity and low dielectric loss $(0.02)$ were simultaneously achieved in the single-crystalline silicon plates after thermal oxidation (ISI structure).
\end{abstract}

Keywords: colossal permittivity; single-crystalline silicon plate; thermal oxidation

\section{Introduction}

High dielectric constant (colossal permittivity, CP) materials are indispensable for producing modern advanced microelectronics and high density storage systems. Thus, much research has focused on high dielectric constant materials. High performance dielectric constant materials must have the following three conditions: (1) stable dielectric properties in a wide range of frequencies and temperatures, (2) larger dielectric constants $\left(\varepsilon_{r}>10^{3}\right)$, and (3) relatively small loss $(\tan \delta<0.1)$. However, a common problem in the study of materials with high dielectric constants is that the dielectric loss may become very large when the dielectric constant is increased. To date, several mechanisms have been proposed to explain the $\mathrm{CP}$ in high dielectric materials $\left(\mathrm{CP}>10^{3}\right)$ [1-11], such as $\mathrm{BaTiO}_{3}$ ceramic oxides [9,10], $\mathrm{CaCu}_{3} \mathrm{Ti}_{4} \mathrm{O}_{12}\left(\mathrm{CCTO}\right.$ [2,5-8]), $\mathrm{NiO}$ [3], $\mathrm{La}_{2 x} \mathrm{Sr}_{x} \mathrm{NiO}_{4}$ [4] (x=1/3 or 1/8), and doped $\mathrm{TiO}_{2}[5,11]$. There are several CP mechanisms, including the barrier layer capacitor mechanism [1,12], the nanoscale atomic dislocation mechanism [13,14], Mott's relation obey the variable range hopping (VRH) mechanism [15], and the electric dipole pinning effect [16,17]. If there are a large number of defects in a polycrystalline material, the space charges caused by the defects could be bounded near the interface among the grains. Due to thermal excitation, these space charges can jump from one place to another, forming a large quantity of carriers (similar to free charge), which is also a mechanism to obtain a high dielectric constant. If these carriers are localized near the lattice defects, a larger dielectric constant and a smaller dielectric loss can be obtained simultaneously. Unfortunately, under the action of the applied electric field, these jumping carriers usually participate in the conduction process of the external circuit, resulting in large leakage related losses $[18,19]$. 
In the inner region of a single-crystalline material, there is no any grain interface for bounding the space charges. Therefore, it is usually considered impossible that both a high dielectric constant and a low dielectric loss can be simultaneously achieved by adding the number of carriers in a single-crystalline material. However, it is possible that, on the surface of a single-crystalline material, an insulating layer can be prepared artificially to isolate the space charge. If so, under an applied electric field, internal polarization can form because positive and negative space charges are separated and accumulated at the top or the bottom surface, respectively. In other words, the inner mobile carriers are bound under the top or the bottom surface due to the insulating layers. Then, a low leakage related loss with a large polarization due to a large amount of space charges can occur, namely, a high dielectric constant and low dielectric loss can be obtained simultaneously.

In our recent work [20], we successfully lowered the dielectric loss of a $\mathrm{TiO}_{2}$ ceramic with richer oxygen vacancies by introducing insulating layers on both the top and the bottom surfaces. We proposed a route to realize high performance $\mathrm{CP}$ by creating multilayer structures of the insulator/semiconductor/insulator (ISI). In this paper, a $\mathrm{SiO}_{2} / \mathrm{Si} / \mathrm{SiO}_{2}$ structure in single-crystal semiconductor $\mathrm{Si}$ wafers by thermal oxidation was obtained by generating an amorphous $\mathrm{SiO}_{2}$ film on the top and the bottom surfaces, and the microstructure and dielectric properties of the $\mathrm{SiO}_{2} / \mathrm{Si} / \mathrm{SiO}_{2}$ structures were studied in detail.

\section{Materials and Methods}

The raw material used in this work was n-type $\mathrm{Si}<100>$. The $\mathrm{Si}$ wafers $\left(1 \times 1 \mathrm{~cm}^{2}\right)$ were cleaned sequentially with $1 \% \mathrm{HF}$ (mass fraction) and alcohol in an ultrasonic bath for 10 min each and dried after each step under an $\mathrm{N}_{2}$ stream. The $\mathrm{Si}$ wafers were put into a tubular furnace for thermal oxidation. The tubular furnace temperature was $1100{ }^{\circ} \mathrm{C}$, and the flow of $\mathrm{O}_{2}$ atmosphere was $10.0 \mathrm{sccm}$ during the thermal oxidation process. After thermal oxidation, the $\mathrm{Si}$ wafers were removed from the tubular furnace and cooled naturally to room temperature. The Si wafers underwent thermal oxidation at $1100{ }^{\circ} \mathrm{C}$ (with $\mathrm{O}_{2}$ ) for $3 \mathrm{~min}, 5 \mathrm{~min}, 10 \mathrm{~min}, 20 \mathrm{~min}, 40 \mathrm{~min}$, and $1 \mathrm{~h}$, respectively. Samples of the thermal oxidation $\mathrm{Si}$ wafers with different $\mathrm{Si}$ wafer resistivity and different $\mathrm{Si}$ wafer thickness were prepared using the control variable method. Ag electrodes $\left(3.14 \mathrm{~mm}^{2}\right)$ were prepared on both sides of the thermal oxidation $\mathrm{Si}$ wafers by magnetron sputtering in an Ar atmosphere $(40.0 \mathrm{sccm})$ for $5 \mathrm{~min}$. The sputtering power was $40 \mathrm{~W}$, and the pressure of the Ar atmosphere was 1.0 Pa during the sputtering process.

The crystal structures of the Si wafers were evaluated by measuring the XRD patterns (RIGAKU D/MAX 3C, The Woodlands, TX, USA) recorded using Ni-filtered CuK $\alpha$ radiation $(\lambda=1.540598 \AA$, scanning range from $20^{\circ}$ to $80^{\circ}$ and step length of $6^{\circ} / \mathrm{min}$ ). The surface morphologies of the Si wafers were investigated using SEM (Hitachi S-570, Tokyo, Japan). Dielectric properties were measured by the impedance analyzer (HP4294A). X-ray photoelectron spectroscopy (XPS, Escalab 250 XI, Thermo Fisher Scientific, Waltham, MA, USA) was also collected from the thermal oxidation $\mathrm{Si}$ wafer samples to assess the valance states of the $\mathrm{Si}$ ions and roughly evaluate the oxygen content.

\section{Results and Discussion}

\subsection{Microstructure Analysis of the Single-Crystal Semiconductor Si Plates after Thermal Oxidation}

The high temperature of thermal oxidation process is usually $900-1200{ }^{\circ} \mathrm{C}$ [21] to form a layer of $\mathrm{SiO}_{2}$ thin films on the $\mathrm{Si}$ surface. It mainly includes three kinds of different methods: dry oxygen oxidation, wet oxidation, and oxygen water vapor oxidation [22,23]. In this paper, the dry oxygen oxidation method was used to thermally oxidize the single-crystal semiconductor Si plates. Figure 1 shows the XRD pattern of a single-crystalline silicon plate before and after thermal oxidation for $3 \mathrm{~min}$. The XRD pattern shows there was only a peak at the $\mathrm{Si}<100>$ crystalline phase, which suggests no new crystalline phase was generated during the thermal oxidation process. The surface morphologies of the above two samples were observed by SEM, as shown in Figure S1 in Supplementary Files. There 
was no grain or grain boundary on the surface of the Si plate, even at a magnification of 90,000 times, which was consistent with the measured XRD results, indicating that the $\mathrm{SiO}_{2}$ film generated by thermal oxidation was amorphous. An amorphous $\mathrm{SiO}_{2}$ thin film $[24,25]$ is a tetrahedral network structure where the oxygen atoms between two tetrahedrons are called bridge bonded oxygen atoms, and those only associated with one tetrahedron are called non-bridge bonded oxygen atoms.

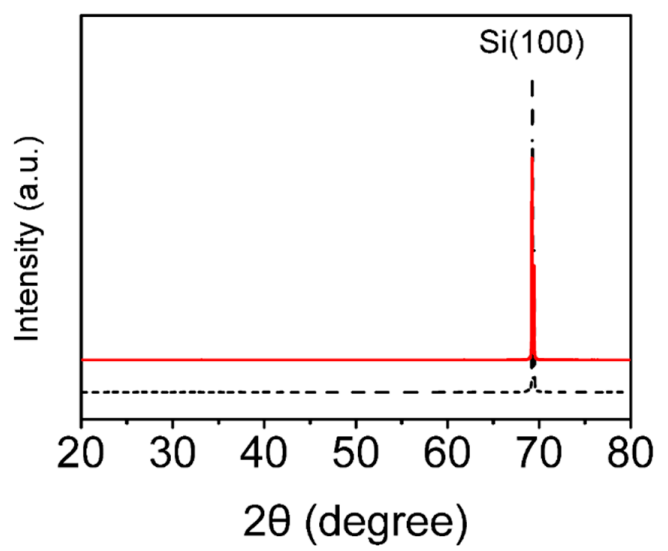

Figure 1. XRD patterns of a single-crystalline silicon plate (thickness $0.7 \mathrm{~mm}$, resistivity $0.001 \Omega \cdot \mathrm{cm}$ ). Raw single-crystalline silicon wafer (black dash line) and after thermal oxidation for $3 \mathrm{~min}$ (red solid line).

\subsection{XPS Analysis and $\mathrm{SiO}_{2}$ Film Thickness Measurement of the Single-Crystalline Silicon Plates after} Thermal Oxidation

To determine the thickness of the $\mathrm{SiO}_{2}$ layer and check the valance state of the $\mathrm{Si}$ and O elements in the thermally oxidized Si plates, we measured the XPS data of both the surface and the inner region using the Ar ion etching process. The results are shown in Figure 2.
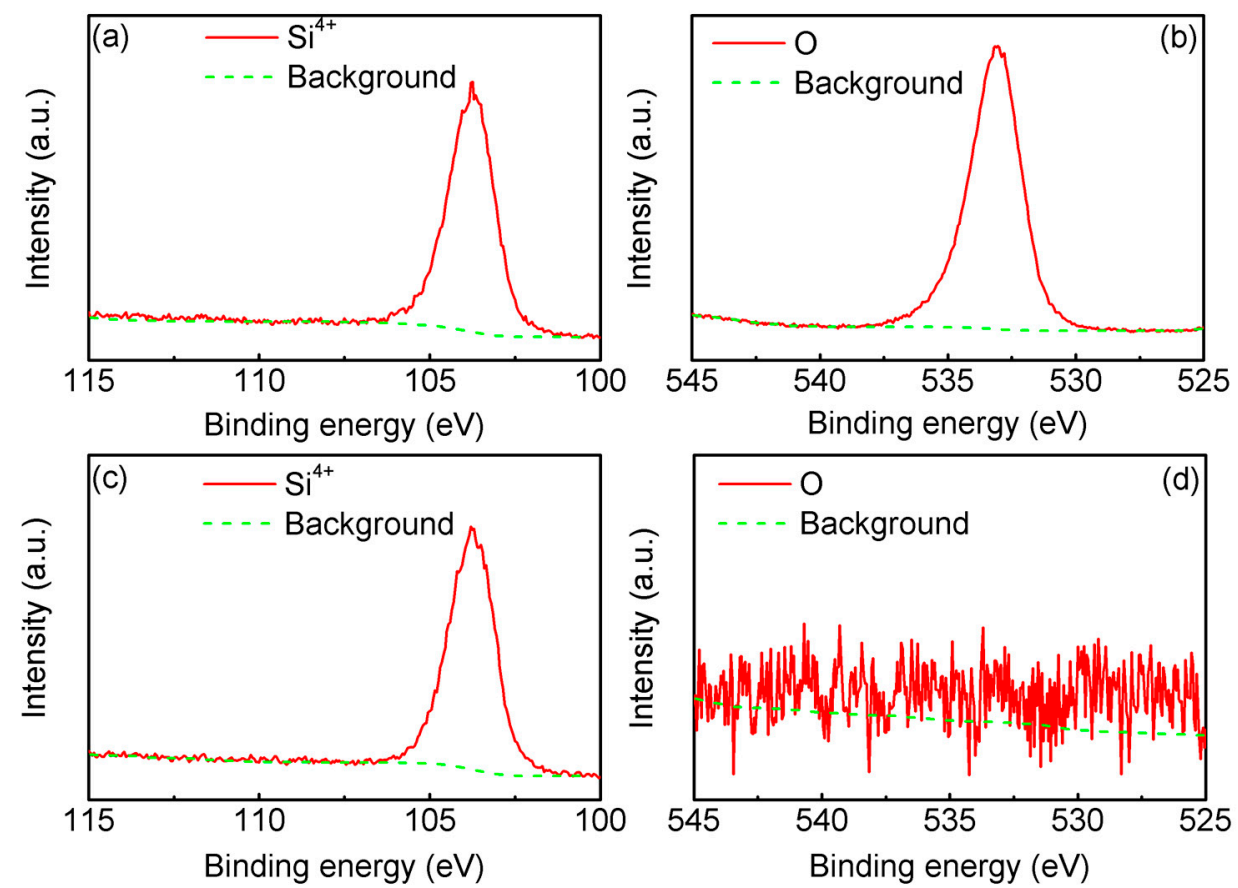

Figure 2. X-ray photoelectron spectroscopy (XPS) data of Si 2p and O 1s electrons for the single-crystalline silicon plates after thermal oxidation ( $3 \mathrm{~min}$ ) before etching using the Ar ion process $(\mathbf{a}, \mathbf{b})$ and after etching using the Ar ion process $(\mathbf{c}, \mathbf{d}) .(\mathbf{a}, \mathbf{c})$ and $(\mathbf{b}, \mathbf{d})$ are the surface XPS data of $\mathrm{Si} 2 \mathrm{p}$ and $\mathrm{O} 1 \mathrm{~s}$, respectively. 
Figure $2 \mathrm{a}$, $\mathrm{b}$ shows the elements ( $\mathrm{Si}$ and $\mathrm{O}$ ) distribution and valence states on the surface of the thermal oxidized single-crystalline silicon plate before etching. The results show that the Si element had only a $\mathrm{Si}^{4+}$ valence state of a Si $2 \mathrm{p}$ orbital $(103.8 \mathrm{eV})$, and the O element had only one peak $(532.9 \mathrm{eV})$. The binding energy of the $\mathrm{Si}-\mathrm{O}$ bond was consistent with that reported in the literature [26,27]. Since the thermal oxidation process of the single-crystalline silicon plates was carried out in an oxygenated atmosphere, $\mathrm{Si}^{4+}$ could not be reduced to low-valence ions at high temperature. According to the atomic content distribution obtained by XPS analysis, the contents of the $\mathrm{Si}$ and O elements on the surface of the $\mathrm{Si}$ sheet before etching were $30.83 \%$ and $57.9 \%$ (that of $\mathrm{C}$ was $11.27 \%$, not shown here), respectively, which further demonstrated that a layer of $\mathrm{SiO}_{2}$ was generated on the surface of the $\mathrm{Si}$ plates after thermal oxidation. When Ar ion etching was used (the etching voltage was $2 \mathrm{kV}$, etching rate of the $\mathrm{SiO}_{2}$ was about $0.14 \mathrm{~nm} / \mathrm{s}$ [28]) after the etching of $220 \mathrm{~s}$, the surface O element was almost impossible to detect, as shown in Figure 2d. Here, the contents of the $\mathrm{Si}$ and $\mathrm{O}$ elements on the surface of Si plates were $89.25 \%$ and $0.5 \%$ (that of $\mathrm{C}$ was $10.25 \%$, not shown here), respectively.

The thickness of the etched $\mathrm{SiO}_{2}$ layers was derived from the product of the etching rate $(0.14 \mathrm{~nm} / \mathrm{s})$ and etching time $(220 \mathrm{~s})$. Therefore, the thickness of the $\mathrm{SiO}_{2}$ obtained after $3 \mathrm{~min}$ of thermal oxidation was approximately $30.8 \mathrm{~nm}$. Deal et al. [22] reported the relationship between the thickness of $\mathrm{SiO}_{2}$ layers generated by the thermal oxidation of $\mathrm{Si}$ plates and the thermal oxidation time, and the corresponding $\mathrm{SiO}_{2}$ thickness was similar to the results we measured. According to the thickness of the single-crystalline silicon plate after thermal oxidation for $3 \mathrm{~min}$, we could evaluate the thickness of other thermal oxidation samples for $5 \mathrm{~min}, 10 \mathrm{~min}, 20 \mathrm{~min}, 40 \mathrm{~min}$, and $1 \mathrm{~h}$, respectively, i.e., $35 \mathrm{~nm}, 48 \mathrm{~nm}, 70 \mathrm{~nm}, 104 \mathrm{~nm}$, and $131 \mathrm{~nm}$. These evaluated $\mathrm{SiO}_{2}$ thicknesses were confirmed by the SEM cross-section pictures seen in Figure 3. Figure 3 shows the cross-section SEM images of a single-crystalline silicon plate (thickness $0.7 \mathrm{~mm}$, resistivity $0.001 \Omega \cdot \mathrm{cm}$ ) that underwent thermal oxidation for various times in the $\mathrm{O}_{2}$ atmosphere. The $\mathrm{SiO}_{2}$ layer thickness of the thermally oxidized silicon plates increased with the increasing thermal oxidation time. From Figure 3, we could evaluate the thickness of thermal oxidation samples for $3 \mathrm{~min}, 5 \mathrm{~min}, 10 \mathrm{~min}, 20 \mathrm{~min}, 40 \mathrm{~min}$, and $1 \mathrm{~h}$, respectively, i.e., $33 \mathrm{~nm}, 38 \mathrm{~nm}, 49 \mathrm{~nm}, 68 \mathrm{~nm}, 110 \mathrm{~nm}$, and $139 \mathrm{~nm}$.
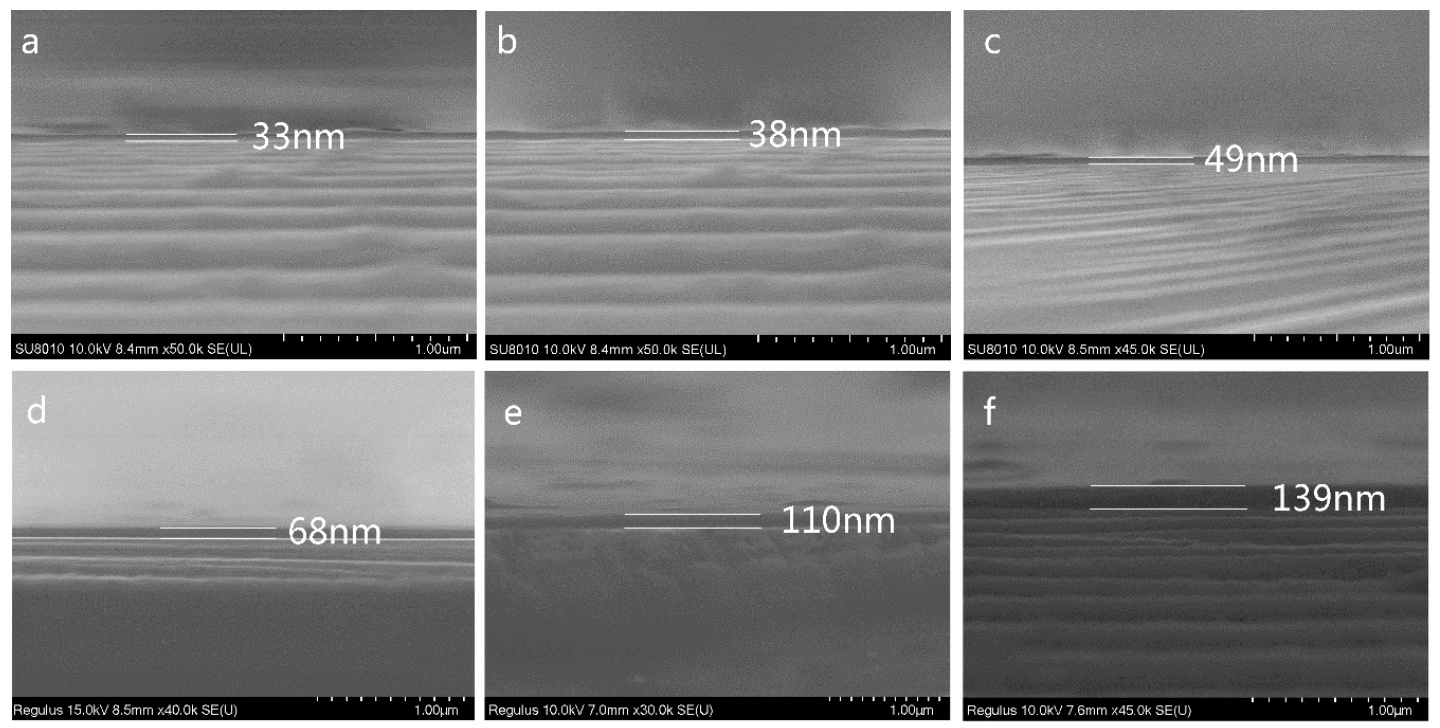

Figure 3. Cross-section SEM images of a single-crystalline silicon plate (thickness $0.7 \mathrm{~mm}$, resistivity $0.001 \Omega \cdot \mathrm{cm}$ ) at different thermal oxidation times (a) $3 \mathrm{~min}$, (b) $5 \mathrm{~min},(\mathbf{c}) 10 \mathrm{~min}$, (d) $20 \mathrm{~min},(\mathbf{e}) 40 \mathrm{~min}$, and (f) $1 \mathrm{~h}$. 


\subsection{Dielectric Properties at Room Temperature of the Single-Crystal Semiconductor Si Plates after Thermal Oxidation}

Figure 4 shows the dielectric permittivity and dielectric loss of the single-crystalline silicon plates (thickness $0.7 \mathrm{~mm}$, resistivity $0.001 \Omega \cdot \mathrm{cm}$ ) that underwent thermal oxidation for various times in the $\mathrm{O}_{2}$ atmosphere. The dielectric permittivity of the thermally oxidized silicon plates decreased with the increasing thermal oxidation time. It was easy to understand that the thickness of the $\mathrm{SiO}_{2}$ generated at the top and the bottom of the silicon plates increased as the thermal oxidation time increased. According to our recent work [20], we found that the dielectric constant was inversely proportional to the thickness of the insulator in the ISI structure (seen in Figure S2 in Supplementary Files). The maximum dielectric permittivity $\left(\sim 1.4 \times 10^{4}\right)$ of the thermally oxidized silicon plates for $3 \mathrm{~min}$ was approximately two times higher than that of the thermally oxidized silicon plates for $1 \mathrm{~h}\left(\sim 0.75 \times 10^{4}\right)$. The CP varied within $15 \%$ with frequency $\left(100-10^{6} \mathrm{~Hz}\right)$ and independent of the temperature (100-250 K, seen in Figure S3 in Supplementary Files). The dielectric constant of all of the thermally oxidized silicon plates were enhanced more than that of the intrinsic single-crystal silicon plates ( 11.9 [29]). The measured dielectric loss of the samples with different thermal oxidation times had no relationship with thermal time on the whole, which decreased with increased thermal oxidation time. The dielectric losses of the all samples were below 0.06 over most of the measured frequency range $\left(10^{2}-10^{6} \mathrm{~Hz}\right)$, and the minimum dielectric loss was $0.02\left(\right.$ at $\left.10^{4}-10^{5} \mathrm{~Hz}\right)$ for the thermally oxidized silicon plates for $1 \mathrm{~h}$. Compared with that of the raw Si wafer (the inset of Figure $4 \mathrm{~b}$ ), the dielectric constant and dielectric loss of all of the thermally oxidized silicon plates were decreased greatly because the carriers were concentrated on the top and the bottom surfaces of the silicon plates due to the $\mathrm{SiO}_{2}$ generated by thermal oxidation, thus no large leakage current was generated, preventing large dielectric loss.

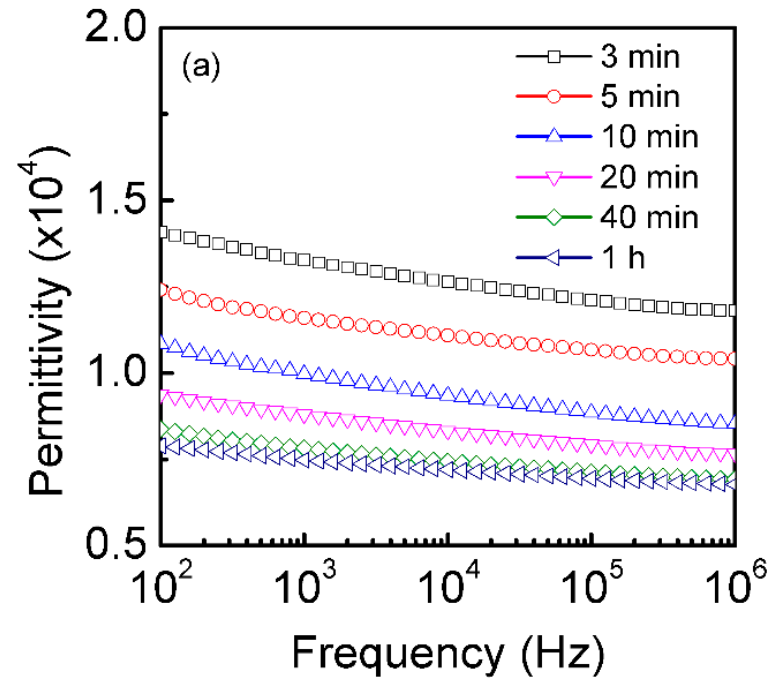

(a)

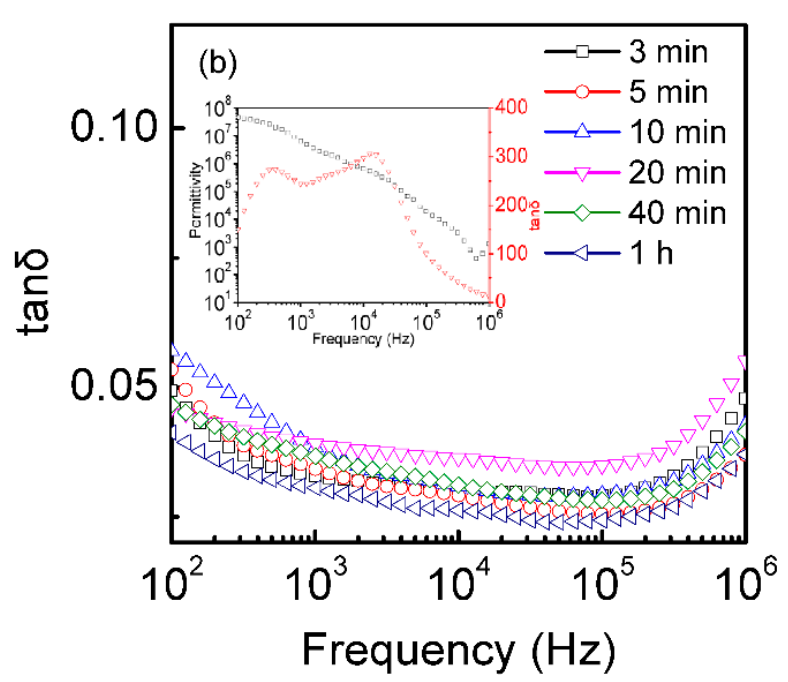

(b)

Figure 4. Frequency dependence of the dielectric properties at room temperature. Dielectric permittivity (a) and dielectric loss (b) of the single-crystalline silicon plates $(0.7 \mathrm{~mm})$ at different thermal oxidation times ( $3 \mathrm{~min}, 5 \mathrm{~min}, 10 \mathrm{~min}, 20 \mathrm{~min}, 40 \mathrm{~min}$, and $1 \mathrm{~h}$ ). The inset figure shows dielectric constant and dielectric loss of the raw single-crystalline silicon wafer (no thermal oxidation).

To further study the effects of different resistivity on the dielectric properties of the silicon plates after oxidation, the dielectric permittivity and dielectric loss of the thermal oxidized Si plates (thickness $0.7 \mathrm{~mm}$ ) with different resistivity at room temperature were assessed, as shown in Figure 5. The CP of the thermally oxidized silicon plates decreased with the increase of the resistivity. It was easy to understand that the larger the resistivity of the single-crystal Si plates was, the lower the 
internal carrier concentration was, which was very crucial to the polarization [20]. The maximum dielectric permittivity at $10^{5} \mathrm{~Hz}\left(\sim 1.23 \times 10^{4}\right)$ was obtained when the resistivity of the silicon plates was $0.001 \Omega \cdot \mathrm{cm}$. The measured dielectric losses of the $0.001 \Omega \cdot \mathrm{cm}$ resistivity sample were below 0.06 over most of the measured frequency range $\left(10^{2}-10^{6} \mathrm{~Hz}\right)$, and the minimum dielectric loss was 0.03 (at $2 \times 10^{4}-10^{5} \mathrm{~Hz}$ ). The CP and dielectric loss changed slightly in the whole frequency range $\left(10^{2}-10^{6} \mathrm{~Hz}\right)$, indicating that the dielectric properties of the thermal oxidized single-crystal Si plates with different resistivity had better frequency stability.

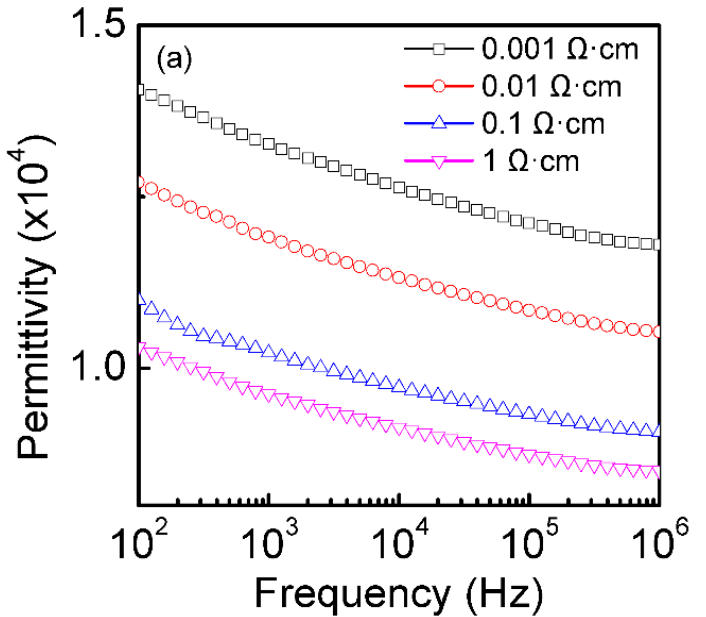

(a)

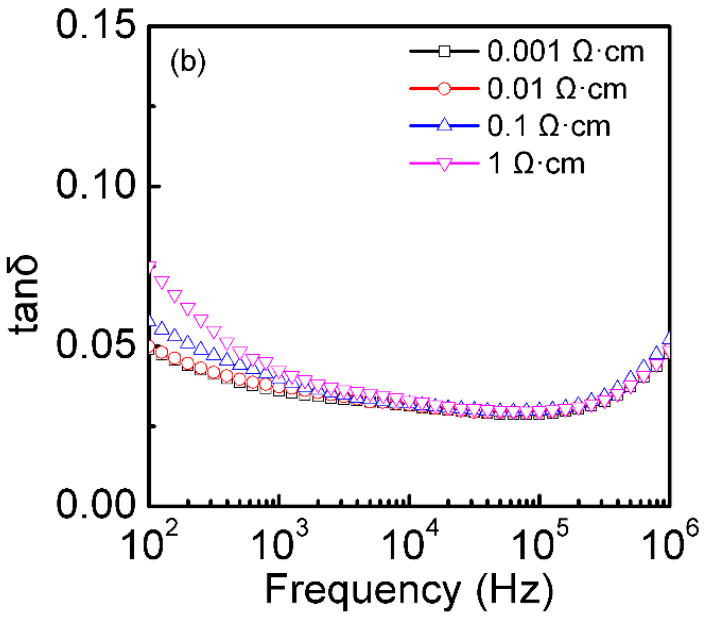

(b)

Figure 5. Frequency dependence of the dielectric properties at room temperature. Dielectric permittivity (a) and dielectric loss $(\mathbf{b})$ of the single-crystalline silicon plates $(0.7 \mathrm{~mm})$ with different resistivity $(0.001,0.01$, 0.1 , and $1 \Omega \cdot \mathrm{cm}$ ) after thermal oxidation for $3 \mathrm{~min}$.

According to the typical formula of a relative dielectric constant:

$$
\varepsilon_{r}=\frac{C \cdot d}{\varepsilon_{0} \cdot S},
$$

here, $\varepsilon_{0}$ was the absolute dielectric constant and $S$ was the surface area of the top and bottom surfaces' electrodes of the thermally oxidized single-crystalline silicon plates, $C$ was the capacitance, and $d$ was the thickness of the single-crystal silicon plates. Usually, $\mathrm{C}$ decreases with the increasing of $\mathrm{d}$, and as a result, $\varepsilon_{\mathrm{r}}$ keeps a constant. It was interesting that the $\varepsilon_{\mathrm{r}}$ of the thermally oxidized Si plates was dependent on $d$ (the thickness of the Si plates). Figure 6 shows the dielectric permittivity and the dielectric loss of the single-crystalline silicon plates (different thicknesses) thermally oxidized in an $\mathrm{O}_{2}$ atmosphere. The dielectric permittivity of the silicon plates increased with the increase of Si plate thickness, and the maximum dielectric permittivity at $100 \mathrm{~Hz}\left(\sim 1.95 \times 10^{4}\right)$ obtained in the $1.0 \mathrm{~mm}$ thick Si plates was approximately 4.2 times higher than that $\left(\sim 0.46 \times 10^{4}\right)$ of the $0.24 \mathrm{~mm}$ thick Si plates, which was due to the measured $C$ that had almost no large change with different thicknesses. This may have been attributed to the large carrier concentration that was plenty big enough for the polarization, which was not dependent on the single-crystalline silicon plates (different thickness). Furthermore, the CP was almost independent of the frequency $\left(100-10^{6} \mathrm{~Hz}\right)$. The measured dielectric losses of the $1.0 \mathrm{~mm}$ sample were below 0.07 over most of the measured frequency range $\left(10^{2}-10^{6} \mathrm{~Hz}\right)$, and the minimum dielectric loss was 0.04 (at $10^{4}-10^{5} \mathrm{~Hz}$ ). Similarly, the CP and the dielectric loss changed slightly in the whole frequency range $\left(10^{2}-10^{6} \mathrm{~Hz}\right)$, indicating that the dielectric properties of the single-crystal Si plates with different thicknesses after thermal oxidation had better frequency stability. 


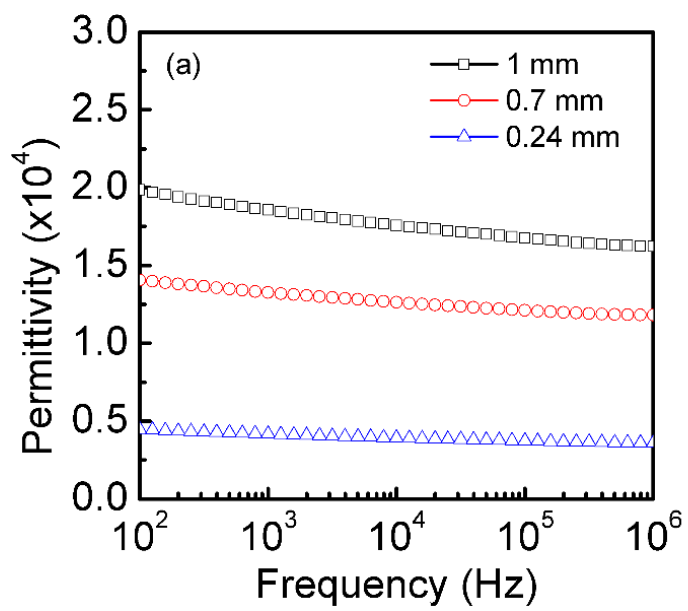

(a)

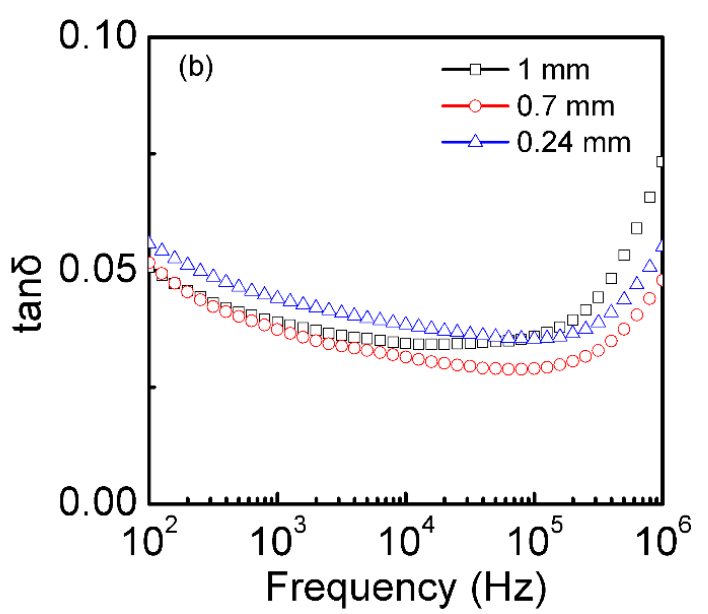

(b)

Figure 6. Frequency dependence of the dielectric properties at room temperature. Dielectric permittivity (a) and dielectric loss (b) of the single-crystalline silicon plates $(0.001 \Omega \cdot \mathrm{cm})$ with different thicknesses $(0.24,0.7$, and $1 \mathrm{~mm})$ after thermal oxidation for $3 \mathrm{~min}$.

\section{Conclusions}

In this study, thin $\mathrm{SiO}_{2}$ insulating layers were generated on the top and the bottom surfaces of single-crystalline silicon plates (n type) via thermal oxidation to obtain an ISI multilayer structure. The experiments were carried out under the conditions of controlling the thermal oxidation time, the resistivity of the Si plates, and the thickness of the Si plates, respectively. The maximum dielectric permittivity $\left(10^{4}\right)$ was obtained. Furthermore, the $\mathrm{CP}$ was almost independent of the frequency $\left(100-10^{6} \mathrm{~Hz}\right)$. The measured dielectric losses of the sample were below 0.07 over most of the measured frequency range $\left(10^{2}-10^{6} \mathrm{~Hz}\right.$ ), and the minimum dielectric loss was 0.02 (at $10^{4}-10^{5} \mathrm{~Hz}$ ). The ISI structure obtained from the single-crystalline silicon plates after thermal oxidation had better dielectric characteristics, that is, high dielectric constant and low dielectric loss could be obtained at the same time.

Supplementary Materials: The following are available online at http:/ /www.mdpi.com/1996-1944/12/7/1102/s1, Figure S1: SEM image of a single-crystalline silicon plate (thickness $0.7 \mathrm{~mm}$, resistivity $0.001 \Omega \cdot \mathrm{cm}$ ). (a) Raw single-crystalline silicon wafer and (b) after thermal oxidation for $3 \mathrm{~min}$, Figure S2: Schematic of colossal permittivity based on the thermal oxidation for $3 \mathrm{~min}$ single-crystalline silicon plates (thickness $0.7 \mathrm{~mm}$, resistivity $0.001 \Omega \cdot \mathrm{cm}$ ) in $\mathrm{O}_{2}$ atmosphere. (a) Insulator/semiconductor/insulator sandwich structure. (b) Sandwich structure applied by an external electrical field. (c) Dielectric constant and thickness of each part in the sandwich structure. $\varepsilon_{\mathrm{r} 1}\left(\varepsilon_{\mathrm{r} 2}\right)$ and $\mathrm{d}_{1}\left(\mathrm{~d}_{2}\right)$ are dielectric constant and thickness of the insulator (semiconductor), respectively. The total thickness of the sandwich structure is labeled as $d$, which is the sum of $d_{1}$ and $d_{2}\left(d_{2}>>d_{1}\right)$, Figure S3: Temperature dependence of the dielectric properties at difference frequency $(500 \mathrm{~Hz}, 1 \mathrm{kHz}, 10 \mathrm{kHz}, 50 \mathrm{kHz}$ and $100 \mathrm{kHz}$ ) were measured from 100 to $450 \mathrm{~K}$. Dielectric permittivity (a) and dielectric loss (b) of the single-crystalline silicon plate (thickness $0.7 \mathrm{~mm}$, resistivity $0.001 \Omega \cdot \mathrm{cm}$ ) after thermal oxidation for $3 \mathrm{~min}$.

Author Contributions: Methodology, F.Z.; software, Y.S., K.L.; validation, Y.S., K.L. and F.Z.; formal analysis, F.Z.; investigation, D.W.; resources, F.Z.; data curation, Y.S.; writing—original draft preparation, Y.S.; writing-review and editing, F.Z.; visualization, D.W.; supervision, D.W.; project administration, F.Z.; funding acquisition, F.Z.

Funding: This work was supported by the National Natural Science Foundation of China (Grant No. 51272166), a project funded by the Priority Academic Program Development of Jiangsu Higher Education Institutions (PAPD).

Conflicts of Interest: The authors declare no conflict of interest.

\section{References}

1. Buscaglia, M.T.; Viviani, M.; Buscaglia, V.; Mitoseriu, L.; Galassi, C. High dielectric constant and frozen macroscopic polarization in dense nanocrystalline $\mathrm{BatiO}_{3}$ ceramics. Phys. Rev. B 2006, 73, 064114. [CrossRef] 
2. Subramanian, M.A.; Dong, L.; Duan, N.; Reisner, B.A.; Sleight, A.W. High Dielectric Constant in $\mathrm{CaCu}_{3} \mathrm{Ti}_{4} \mathrm{O}_{12}$ and $\mathrm{CaCu}_{3} \mathrm{Ti}_{3} \mathrm{FeO}_{12}$ Phases. J. Solid State Chem. 2000, 151, 323. [CrossRef]

3. Junbo, W.; Ce-Wen, N.; Yuanhua, L.; Yuan, D. Giant Dielectric Permittivity Observed in Li and Ti Doped NiO. Phys. Rev. Lett. 2002, 89, 217601.

4. Krohns, S.; Lunkenheimer, P.; Kant, C.; Pronin, A.V.; Brom, H.B.; Nugroho, A.A.; Diantoro, M.; Loidl, A. Colossal dielectric constant up to gigahertz at room temperature. Appl. Phys. Lett. 2009, 94, 122903. [CrossRef]

5. Wanbiao, H.; Yun, L.; Ray, L.W.; Terry, J.F.; Lasse, N.; Amanda, S.; Melanie, K.; Paul, S.; Bill, G.; Hua, C.; et al. Electron-pinned defect-dipoles for high-performance colossal permittivity materials. Nat. Mater. 2013, 12, 821.

6. Tkach, A.; Okhay, O.; Almeida, A. Giant dielectric permittivity and high tunability in Y-doped $\mathrm{SrTiO}_{3}$ ceramics tailored by sintering atmosphere. Acta Mater. 2017, 130, 249-260. [CrossRef]

7. Adams, T.B.; Sinclair, D.C.; West, A.R. Giant Barrier Layer Capacitance Effects in $\mathrm{CaCu}_{3} \mathrm{Ti}_{4} \mathrm{O}_{12}$ Ceramics. Adv. Mater. 2002, 14, 1321-1323. [CrossRef]

8. Guillemet-Fritsch, S.; Valdez-Nava, Z.; Tenailleau, C. Colossal Permittivity in Ultrafine Grain $\mathrm{Size} \mathrm{BaTiO}_{3-x}$ and $\mathrm{Ba}_{0.95} \mathrm{La}_{0.05} \mathrm{TiO}_{3-\mathrm{x}}$ Materials. Adv. Mater. 2008, 20, 551. [CrossRef]

9. Ramesh, S.; Shutzberg, B.A.; Huang, C.; Gao, J.; Giannelis, E.P. Dielectric nanocomposites for integral thin film capacitors: Materials design, fabrication and integration issues. IEEE Trans. Adv. Packag. 2003, 26, 17-24. [CrossRef]

10. Phansamdaeng, P.; Khemprasit, J. Study on magnetic and dielectric properties of $\mathrm{BaTiO}_{3} / \mathrm{MnCr}_{0.2} \mathrm{Fe}_{1.8} \mathrm{O}_{4}$ composite material. J. Alloys Compd. 2019, 776, 105-110. [CrossRef]

11. Fan, J.T.; Leng, S.L.; Cao, Z.Z.; He, W.Y.; Gao, Y.F.; Liu, J.R.; Li, G.R. Colossal permittivity of Sb and Ga co-doped rutile $\mathrm{TiO}_{2}$ ceramics. Ceram. Int. 2019, 45, 1001-1010. [CrossRef]

12. Li, M.; Feteira, A.; Sinclair, D.C.; West, A.R. Influence of Mn doping on the semiconducting properties of $\mathrm{CaCu}_{3} \mathrm{Ti}_{4} \mathrm{O}_{12}$ ceramics. Appl. Phys. Lett. 2006, 88, 232903. [CrossRef]

13. Zhu, Y.; Zheng, J.C.; Wu, L.; Frenkel, A.I.; Hanson, J.; Northrup, P.; Ku, W. Nanoscale Disorder in $\mathrm{CaCu}_{3} \mathrm{Ti}_{4} \mathrm{O}_{12}$ : A New Route to the Enhanced Dielectric Response. Phys. Rev. Lett. 2007, 99, 037602. [CrossRef] [PubMed]

14. Fang, T.T.; Wang, Y.H.; Kuo, J.C. Role of strained nano-regions in the formation of subgrains in $\mathrm{CaCu}_{3} \mathrm{Ti}_{4} \mathrm{O}_{12}$ J. Appl. Phys. 2011, 110, 024103. [CrossRef]

15. Zhang, L.; Tang, Z.-J. Polaron relaxation and variable-range-hopping conductivity in the giant-dielectric-constant material $\mathrm{CaCu}_{3} \mathrm{Ti}_{4} \mathrm{O}_{12}$. Phys. Rev. B 2004, 70, 174306. [CrossRef]

16. Zhao, X.; Liu, P. Dieletric and electric relaxations induced by the complex defect clusters in $(\mathrm{Yb}+\mathrm{Nb})$ co-doped rutile $\mathrm{TiO}_{2}$ ceramics. J. Am. Ceram. Soc. 2017, 100, 3505-3513. [CrossRef]

17. Yang, C.; Sun, E.W.; Yang, B.; Cao, W.W. Theoretical study on local domain pinning effect due to defect dipole alignment. J. Phys. D Appl. Phys. 2018, 51, 415303. [CrossRef]

18. Jonscher, A.K. The 'universal' dielectric response. Nature 1977, 267, 673-679. [CrossRef]

19. Yubero, F.; Tougaard, S.; Elizalde, E.; Sanz, J.M. Dielectric loss function of $\mathrm{Si}$ and $\mathrm{SiO}_{2}$ from quantitative analysis of REELS spectra. Surf. Interface Anal. 1993, 20, 719-726. [CrossRef]

20. Liu, K.; Sun, Y.; Zheng, F.; Tse, M.-Y.; Sun, Q.; Liu, Y.; Hao, J. A General Strategy to Achieve Colossal Permittivity and Low Dielectric Loss through Constructing Insulator/Semiconductor/Insulator Multilayer Structures. J. Low Temp. Phys. 2018, 192, 346-358. [CrossRef]

21. De Almeida, R.N.C.; Goncalves, S.; Baumvol, I.J.R. Dynamics of thermal growth of silicon oxide films on Si. Phys. Rev. B 2000, 61, 12992. [CrossRef]

22. Deal, B.E.; Grove, A.S. General Relationship for the Thermal Oxidation of Silicon. J. Appl. Phys. 1965, 36, 3770-3778. [CrossRef]

23. Deepthi, G.; Christos, G.T. Diffusion-reaction modeling of silicon oxide interlayer growth during thermal annealing of high dielectric constant materials on silicon. Phys. Rev. B 2008, 77, 205304.

24. Brugemann, L.; Bloch, R.; Press, W.; Gerlach, P. Surface and interface topography of amorphous $\mathrm{SiO}_{2}$ /crystalline $\mathrm{Si}$ (100) studied by X-ray diffraction. J. Phys. Condens. Matter 1990, 2, 8869. [CrossRef]

25. He, G.; Liu, M.; Zhu, L.Q.; Chang, M.; Fang, Q.; Zhang, L.D. Effect of postdeposition on the thermal stability and structural characteristics of sputtered $\mathrm{HfO}_{2}$ films on $\mathrm{Si}(100)$. Sur. Sci. 2005, 576, 67-75. [CrossRef]

26. Mitchell, D.F.; Clark, K.B.; Bardwell, J.A.; Lennard, W.N.; Massoumi, G.R.; Mitchell, I.V. Film thickness measurements of $\mathrm{SiO}_{2}$ by XPS. Surf. Interface Anal. 1994, 21, 44-50. [CrossRef] 
27. Seah, M.P.; Spencer, S.J. Ultrathin $\mathrm{SiO}_{2}$ on $\mathrm{Si}$ IV. Intensity measurement in XPS and deduced thickness linearity. Surf. Interface Anal. 2003, 35, 515-524. [CrossRef]

28. Seah, M.P. Ultrathin $\mathrm{SiO}_{2}$ on $\mathrm{Si}$ II. Issues in quantification of the oxide thickness. Surf. Interface Anal. 2002, 33, 640-652. [CrossRef]

29. Ng, C.Y.; Chen, T.P.; Ding, L.; Liu, Y.; Tse, M.S.; Fung, S.; Dong, Z.L. Static dielectric constant of isolated silicon nanocrystals embedded in $\mathrm{SiO}_{2}$ thin film. Appl. Phys. Lett. 2006, 88, 63103. [CrossRef] 